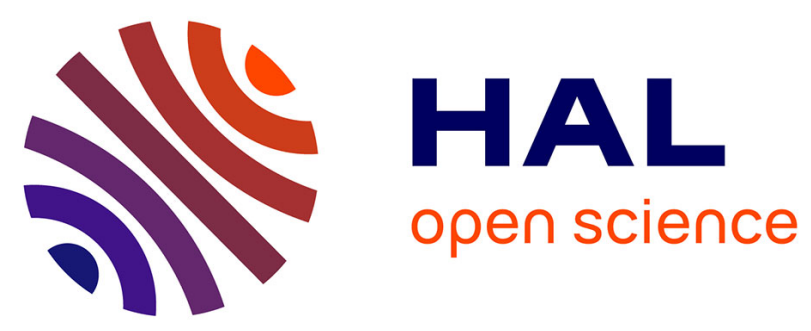

\title{
$34 \mathrm{~W}$ continuous wave Nd:YAG single crystal fiber laser emitting at $946 \mathrm{~nm}$
}

Xavier Délen, Igor Martial, Julien Didierjean, Nicolas Aubry, Damien Sangla, François Balembois, Patrick Georges

\section{> To cite this version:}

Xavier Délen, Igor Martial, Julien Didierjean, Nicolas Aubry, Damien Sangla, et al.. 34 W continuous wave Nd:YAG single crystal fiber laser emitting at $946 \mathrm{~nm}$. Applied Physics B - Laser and Optics, 2011, 104 (1), pp.1-4. 10.1007/s00340-011-4638-5 . hal-00617546

HAL Id: hal-00617546

https://hal-iogs.archives-ouvertes.fr/hal-00617546

Submitted on 29 Aug 2011

HAL is a multi-disciplinary open access archive for the deposit and dissemination of scientific research documents, whether they are published or not. The documents may come from teaching and research institutions in France or abroad, or from public or private research centers.
L'archive ouverte pluridisciplinaire HAL, est destinée au dépôt et à la diffusion de documents scientifiques de niveau recherche, publiés ou non, émanant des établissements d'enseignement et de recherche français ou étrangers, des laboratoires publics ou privés. 


\title{
$34 \mathrm{~W}$ continuous wave $\mathrm{Nd}$ :YAG single crystal fiber laser emitting at $946 \mathrm{~nm}$.
}

\author{
Xavier Délen, ${ }^{1, *}$ Igor Martial, ${ }^{1,2}$ Julien Didierjean, ${ }^{2}$ Nicolas Aubry, ${ }^{2}$ Damien \\ Sangla, ${ }^{1,3}$ François Balembois, ${ }^{1}$ and Patrick Georges ${ }^{1}$ \\ ${ }^{1}$ Laboratoire Charles Fabry de l'Institut d'Optique, CNRS, Université Paris-Sud, RD 128, France \\ ${ }^{2}$ Fibercryst SAS, La Doua-Bâtiment l'Atrium, Boulevard Latarjet, F- 69616 Villeurbanne Cedex, France \\ ${ }^{3}$ Université de Lyon, CNRS, UMR5620, Laboratoire de Physico-Chimie des Matériaux
}

Luminescents,

F-69622 Villeurbanne Cedex, France

*Corresponding author: xavier.delen@institutoptique.fr

Phone number: +33164533438

\begin{abstract}
Taking advantage of the pump beam confinement and the excellent thermal management offered by $\mathrm{Nd}$ :YAG single crystal fibers, we demonstrated a maximum output power of $34 \mathrm{~W}$ at $946 \mathrm{~nm}$ for an incident pump power of $86 \mathrm{~W}$. A high slope efficiency of $53 \%$ was obtained. There was no rollover observed in the efficiency curves and the maximum output power was only limited by the available pump power.
\end{abstract}

Recent developments of laser sources using the ${ }^{4} \mathrm{~F}_{3 / 2}{ }^{4} \mathrm{I}_{9 / 2}$ transition of Nd:YAG to obtain emission at $946 \mathrm{~nm}$, have been mostly driven by the demand of high power blue laser sources. Frequency doubled $946 \mathrm{~nm}$ lasers have numerous potential applications such as biological and medical diagnostics, trace gas detection, Raman spectroscopy. UV light generation which can be obtained by frequency quadrupling is also of great interest for many applications such as ozone remote sensing or writing of fiber Bragg grating.

Since the first demonstrations of a diode-pumped Nd:YAG quasi three level laser in 1987 [1,2], the development of high brightness diode-pumped sources has lead to the design of multiwatt continuous-wave lasers. The highest $\mathrm{cW}$ power ever achieved at $946 \mathrm{~nm}$ are in the range of the few ten's of watts : $15 \mathrm{~W}$ in a bulk end-pumped configuration [3], $25 \mathrm{~W}$ with a thin disk laser [4] and $105 \mathrm{~W}$ with a planar waveguide [5]. These output power values are far below what can be obtained with Nd:YAG for $1064 \mathrm{~nm}$ or $1338 \mathrm{~nm}$ four level transitions producing over hundred watts [6,7]. Indeed, the design of a high power $946 \mathrm{~nm} \mathrm{Nd:YAG} \mathrm{laser} \mathrm{is} \mathrm{difficult} \mathrm{for} \mathrm{several} \mathrm{reasons.}$ It is a quasi three level transition and the emission cross section is about one order of magnitude lower than at $1064 \mathrm{~nm}$. It implies working with high pump intensities in order to obtain efficient laser operation. It is therefore necessary to focus the pump beam on a small diameter. Using typical high power fiber coupled laser diodes (for example with core diameter of $400 \mu \mathrm{m}$ and a numerical aperture of 0.22), the pump beam Rayleigh length is relatively short and the crystal length is then limited to a few millimeters. To ensure a good overlap between pump 
and laser beams and a large overall absorption, a high doping concentration has to be used, typically in the order of $1 \%$. This leads limitation of the performance at $946 \mathrm{~nm}$ in multiple ways. Firstly, non radiative effects as fluorescence quenching and energy transfer upconversion occcur at this doping level. These processes do not only limit the population inversion but also induce an extra heat load which contributes to the crystal temperature increase. Secondly, the high absorption coefficient leads to high local temperature increase, particularly on the pumped face of the crystal. The temperature gradients induce signal beam deformations and mechanical stress which can even lead to the crystal fracture. Moreover, crystal properties such as thermal conductivity and thermooptic coefficient also evolve in a disadvantageous way with temperature inducing higher thermal lensing [8,9]. Finally, the population of the lower level increases with temperature and induces more reabsorption losses and shifts the oscillation threshold.

To keep both high pump intensity and low temperature increase different pump geometries have been used. Bonding of undoped caps to a laser crystal is one way to limit thermal effects caused by the deformation of the crystal faces. This technique was tested in a longitudinally-pumped, 1.1-at.\% Nd:YAG composite crystal, but significant degradation of laser performance at $946 \mathrm{~nm}$ was observed for pump powers in excess of $30 \mathrm{~W}\left(\mathrm{M}^{2}=13\right.$ at maximum pump power) [3]. The thin disk configuration represents a more efficient way to limit the temperature while allowing high pump intensity via multi-pass pumping. It has been used with the quasi three level transition in Nd:YAG but the low emission cross section requires to work with small pump beam diameters to have enough gain. It results in thermal effects which limit the power scaling $[4,10]$. Another way is optical guiding: pump confinement allows the use of Nd:YAG crystals with lower doping concentration and to reduce thermal effects. Pump guiding has been successfully used in a double clad $20 \mathrm{~mm}$ long planar waveguide with a $0.6 \% \mathrm{Nd}^{3+}$ doping concentration [5]. Even if the output power was the highest with $105 \mathrm{~W}$, the beam quality was very limited in the non-guided direction. For a $35 \mathrm{~W}$ output power, the $\mathrm{M}^{2}$ beam quality factor was given to be respectively 2.8 and 56 in the guided and non-guided direction [11].

Nd:YAG single crystal fibers use the same concept of pump guiding but with lower doping concentration $(0.2 \%)$ and longer gain medium $(50 \mathrm{~mm})$ [12]. As opposed to the planar waveguide, the signal beam is in free propagation in the single crystal fiber, and its profile is defined by a cavity with two external mirrors for mode filtering. The concept of single crystal fiber has already been used successfully for a quasi-three level laser: the Yb:YAG with an output power of $50 \mathrm{~W}$ at $1030 \mathrm{~nm}$ [13]. Consequently, this laser crystal geometry seems to have a good potential for the development of high power quasi-three level Nd:YAG lasers at $946 \mathrm{~nm}$.

In this paper, we report, for the first time to our knowledge, laser operation at $946 \mathrm{~nm}$ with a Nd:YAG single crystal fiber. By Finite Element Analysis (FEA), we firstly estimate the potential of this geometry compared to standard bulk crystals in terms of temperature. Then we present experimental results : temperature measurement by infrared imaging and performance of the Nd:YAG single crystal fiber at $946 \mathrm{~nm}$. 
Compared to a classical Nd:YAG crystal, single crystal fibers have two specificities : the low doping concentration $(0.2 \%)$ associated with a long length $(50 \mathrm{~mm})$ and the small section $(1 \mathrm{~mm}$ diameter). In order to understand the interest of this geometry, we carried out a comparison with a set of FEA temperature modelization for different Nd:YAG bulk crystals ( $1 \%$ or $0.2 \%$ doping rate with a square $3 \times 3 \mathrm{~mm}$ section) and for a Nd:YAG single crystal fiber ( $0.2 \%$ doping rate and $1 \mathrm{~mm}$ diameter). For the simulation, no attention was paid on the crystal lengths as we calculated the temperature of the pumped face assuming a radial heat flow. In order to simplify the calculations, we supposed also a perfect contact between the Nd:YAG and its mount, no saturation of absorption and a heat source coming only from the quantum defect between $808 \mathrm{~nm}$ and $946 \mathrm{~nm}$ (14.6\%). The pump power was set at $86 \mathrm{~W}$ over a spot of $500 \mu \mathrm{m}$ diameter: those conditions corresponded to the experimental setup described in the following. Figure 1 shows the temperature rise maps which were obtained as the results of the simulations. Lowering the doping concentration from $1 \%$ to $0.2 \%$ distributes the pumping heat load over a longer length and induces a significant decrease of the maximal temperature rises by over three times (from $194^{\circ} \mathrm{C}$ to $51^{\circ} \mathrm{C}$ ). The small diameter of the single crystal fiber also induces a temperature reduction by over a factor of two (from $51^{\circ} \mathrm{C}$ to $19^{\circ} \mathrm{C}$ ) by bringing the heat sink closer to the heat source.

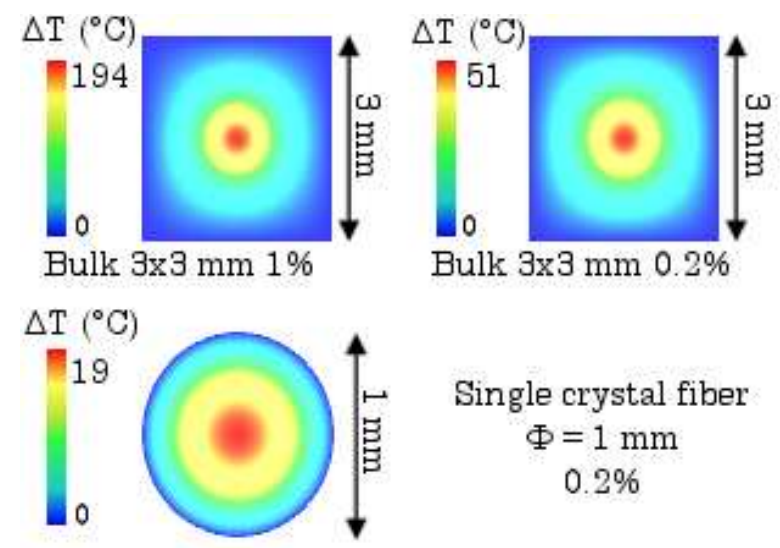

Fig. 1. Temperature rise maps calculated using finite elements analysis.

Consequently, the single crystal fiber geometry could be very useful to reduce the temperature increase and the associated gradient. However, the reduction of the transverse section led also to the reduction of the exchange surface with the mount. Consequently, the heat transfer coefficient between the mount and the single crystal fiber need to be as high as possible in order to take all the benefit of this geometry. This key point was experimentally investigated on a $0.2 \% \mathrm{Nd}$ :YAG single crystal fiber with a diameter of $1 \mathrm{~mm}$ integrated in a water cooled TARANIS module provided by Fibercryst. The thermal contact between the module and the heat sink is ensured by a carbon foil. The water cooling temperature was $25^{\circ} \mathrm{C}$ during the experiment. The measurements were carried out on the pumped face with a thermal camera and a ZnSe beam splitter, in a setup similar to the one used by Chénais et al. [14]. Figure 2 shows the temperature increase map of the crystal for a pump power of $86 \mathrm{~W}$. The temperature difference between the edge of the single crystal fiber and the crystal mount was found to be about $5^{\circ} \mathrm{C}$. This very 
low difference shows the high quality of the thermal contact between the single crystal fiber and the cooling mount (copper block). It reveals also a maximal temperature increase of $31^{\circ} \mathrm{C}$. This value was higher than the one calculated by FEA analysis. It is due to the higher quantum defect between the pump photons and fluorescence photons which is centered around $1134 \mathrm{~nm}$ whereas the laser emits at $946 \mathrm{~nm}$. However, the temperature raise was kept reasonably small even at this high pumping power of $86 \mathrm{~W}$ predicting good performance for $946 \mathrm{~nm}$ laser operation.

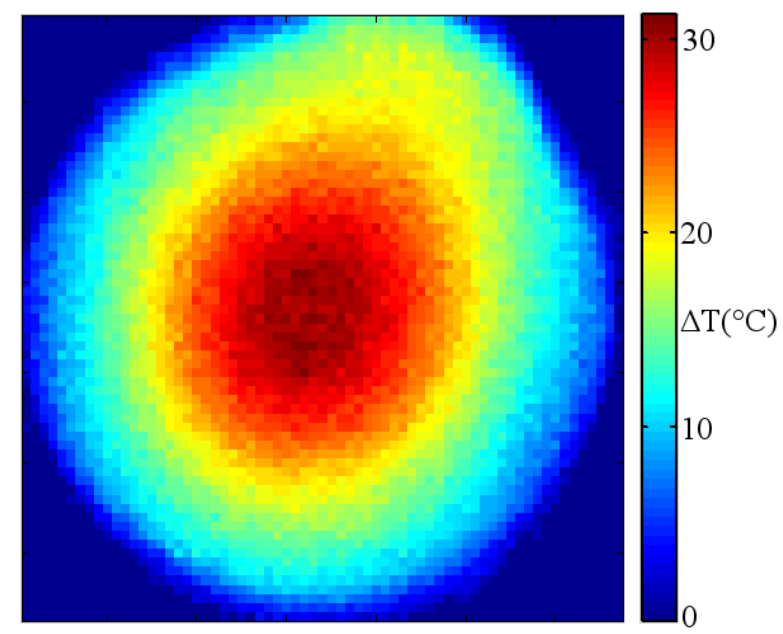

Fig. 2. Temperature increase map of the input face of a $0.2 \%$ doped Nd:YAG single crystal fiber under $86 \mathrm{~W}$ diode pumping over $500 \mu \mathrm{m}$ at $808 \mathrm{~nm}$.

As shown on figure 3, a simple linear cavity made of two concave mirrors was used for the experiment. The dichroïc meniscus $M_{1}$ had a radius of curvature of $100 \mathrm{~mm}$, was highly reflective at $946 \mathrm{~nm}$ and had a low reflectivity at both $808 \mathrm{~nm}$ and $1064 \mathrm{~nm}$ in order to prevent parasitic oscillation. For the output coupler, we used concave mirrors with a radius of curvature of $100 \mathrm{~mm}$, a high transmission at $1064 \mathrm{~nm}(\mathrm{~T}>80 \%)$ and transmission of $2 \%, 5 \%, 10 \%$ and $15 \%$ at $946 \mathrm{~nm}$. The facets of the single crystal fiber were anti-reflection coated for a broadband spectral range between $600 \mathrm{~nm}$ and $1100 \mathrm{~nm}$. The Nd:YAG crystal was $0.2 \%$ doped, $50 \mathrm{~mm}$ long and had a diameter of $1 \mathrm{~mm}$. The water cooling temperature was set at $14^{\circ} \mathrm{C}$ during the experiment. The pump beam was delivered by a laser diode module coupled in a $400 \mu \mathrm{m}$ core diameter fiber with a numerical aperture of 0.22 . The output of the fiber was imaged inside the single crystal fiber using two doublets of focal length $60 \mathrm{~mm}$ and $80 \mathrm{~mm}$. The maximum nominal output power of the diode was $110 \mathrm{~W}$ and the maximum incident pump power on the crystal was $86 \mathrm{~W}$. The lasing wavelength was monitored with an optical spectrum analyzer and only laser emission at $946 \mathrm{~nm}$ has been observed. The output power versus the incident pump power is shown on figure 4 for the different transmissions of the output coupler. 


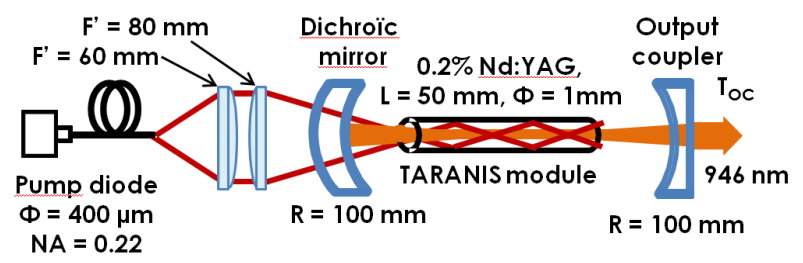

Fig. 3. Experimental setup.

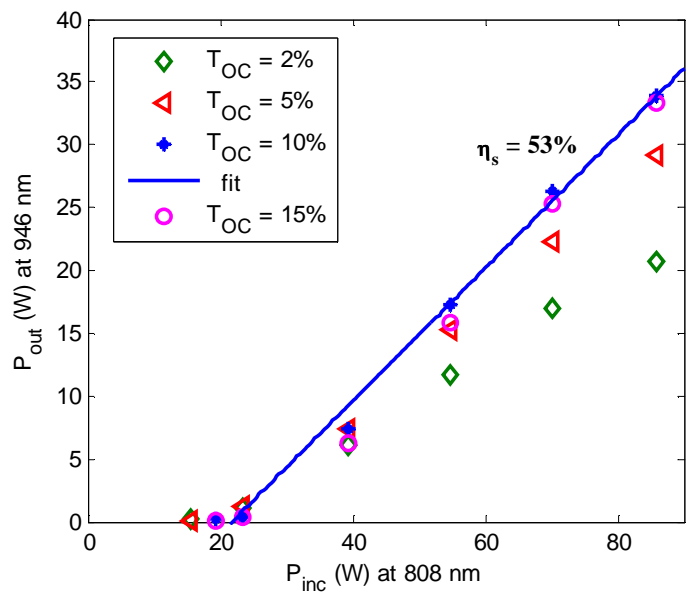

Fig. 4. Laser output power versus incident pump power for different output couplers.

The threshold was found for an incident pump power between $15 \mathrm{~W}$ and $20 \mathrm{~W}$. The maximal slope efficiency was obtained for an output coupler with a $10 \%$ transmission and reached $53 \%$. The maximum output power was $34 \mathrm{~W}$ for an incident pump power of $86 \mathrm{~W}$ which gives an optical conversion efficiency of $39.5 \%$. At this power level, the $\mathrm{M}^{2}$ beam quality factor was below 5 in both directions. In addition, no rollover was observed in the efficiency curves showing the limited impact of the temperature rise and thermal lensing provided by the $1 \mathrm{~mm}$ diameter single crystal fiber together a very efficient thermal management.

In conclusion, we have demonstrated that high power Nd:YAG $946 \mathrm{~nm}$ laser design is possible using single crystal fiber configuration. It offers good thermal management and provides pump energy confinement. A total output power of $34 \mathrm{~W}$ was obtained with high slope efficiency of $53 \%$ and with a relatively good beam quality. To the best of our knowledge, it is the highest output power ever reported for an end-pumped Nd:YAG laser emitting at $946 \mathrm{~nm}$ with a signal beam in free propagation in the laser cavity. It is also the highest brightness for a $946 \mathrm{~nm}$ laser source at this level of power.

Further power scaling can be considered since no roll over has been observed in the efficiency curves. The total output power was only limited by the available pump power. In particular, the full potential of the single crystal fibers could be used in a dual end pump configuration.

Xavier Délen acknowledges the DGA (French Ministry of Defense) for the partial funding of his PhD and Fibercryst for the loan of the TARANIS-Nd module. 


\section{References}

1. T. Y. Fan, and R. L. Byer, "Continuous-wave operation of a room-temperature, diode-laser-pumped, 946 nm Nd:YAG laser, " Opt. Lett. 12, 809-811 (1987).

2. W. P. Risk, and W. Lenth, "Room-temperature, continuous-wave, $946 \mathrm{~nm} \mathrm{Nd:YAG} \mathrm{laser} \mathrm{pumped} \mathrm{by}$ laser diode arrays and intracavity frequency doubling to 473 nm, " Opt. Lett. 12, 993-995 (1987).

3. R. Zhou, E. B. Li, H. F. Li, P. Wang, and J. Q. Yao, "Continuous-wave, 15.2 W diode-end-pumped Nd : YAG laser operating at 946 nm," Opt. Lett. 31, 1869-1871 (2006).

4. G. Jiancun, S. Jochen, and G. Adolf, "25-W Diode-Pumped Continuous-Wave Quasi-Three-Level Nd:YAG Thin Disk Laser," Proc. OSA, p. TuB34 (2005).

5. J. I. Mackenzie, "Power-scaling Nd:YAG's quasi-four-level transition," Proc. SPIE 7578, (2010).

6. G. Zhang, H. Y. Zhu, C. H. Huang, J. Chen, Y. Wei, and L. X. Huang, "Diode-side-pumped Nd:YAG laser at 1338 nm," Opt. Lett. 34, 1495-1497 (2009).

7. R. Wilhelm, D. Freiburg, M. Frede, D. Kracht, and C. Fallnich, "Design and comparison of composite rod crystals for power scaling of diode end-pumped Nd:YAG lasers," Opt. Express 17, 8229-8236 (2009).

8. R. L. Aggarwal, D. J. Ripin, J. R. Ochoa, and T. Y. Fan, "Measurement of thermo-optic properties of Y3A15O12, Lu3Al5O12, YAIO(3), LiYF4, LiLuF4, BaY2F8, KGd(WO4)(2), and KY(WO4)(2) laser crystals in the 80-300 K temperature range," J. Appl. Phys. 98, 14 (2005).

9. A. I. Zagumennyi, G. B. Lutts, P. A. Popov, N. N. Sirota, and I. A. Shcherbakov, "The Thermal Conductivity of YAG and YSAG Laser Crystals," Laser Phys. 3, 1064-1065 (1993).

10. N. Pavel, K. Lunstedt, K. Petermann, and G. Huber, "Multipass pumped Nd-based thin-disk lasers: continuous-wave laser operation at 1.06 and $0.9 \mathrm{mu} \mathrm{m}$ with intracavity frequency doubling," Appl. Opt. 46, 8256-8263 (2007).

11. J. I. Mackenzie, "An efficient high-power 946 nm Nd:YAG planar waveguide laser," Appl. Phys. B 97, (2009).

12. J. Didierjean, M. Castaing, F. Balembois, P. Georges, D. Perrodin, J. M. Fourmigue, K. Lebbou, A. Brenier, and O. Tillement, "High-power laser with Nd : YAG single-crystal fiber grown by the micro-pullingdown technique," Opt. Lett. 31, 3468-3470 (2006).

13. D. Sangla, I. Martial, N. Aubry, J. Didierjean, D. Perrodin, F. Balembois, K. Lebbou, A. Brenier, P. Georges, O. Tillement, and J. M. Fourmigue, "High power laser operation with crystal fibers," Appl. Phys. B 97, 263-273 (2009).

14. S. Chénais, S. Forget, F. Druon, F. Balembois, and P. Georges, "Direct and absolute temperature mapping and heat transfer measurements in diode-end-pumped Yb:YAG," Appl. Phys. B 79, 221-224 (2004). 
Fig. 1. Temperature map calculated using finite elements analysis.

Fig. 2. Temperature increase map of the input face of a $0.2 \%$ doped Nd:YAG single crystal fiber under $86 \mathrm{~W}$ diode pumping over $500 \mu \mathrm{m}$ at $808 \mathrm{~nm}$.

Fig. 3. Experimental setup.

Fig. 4. Laser output power versus incident pump power for different output couplers. 

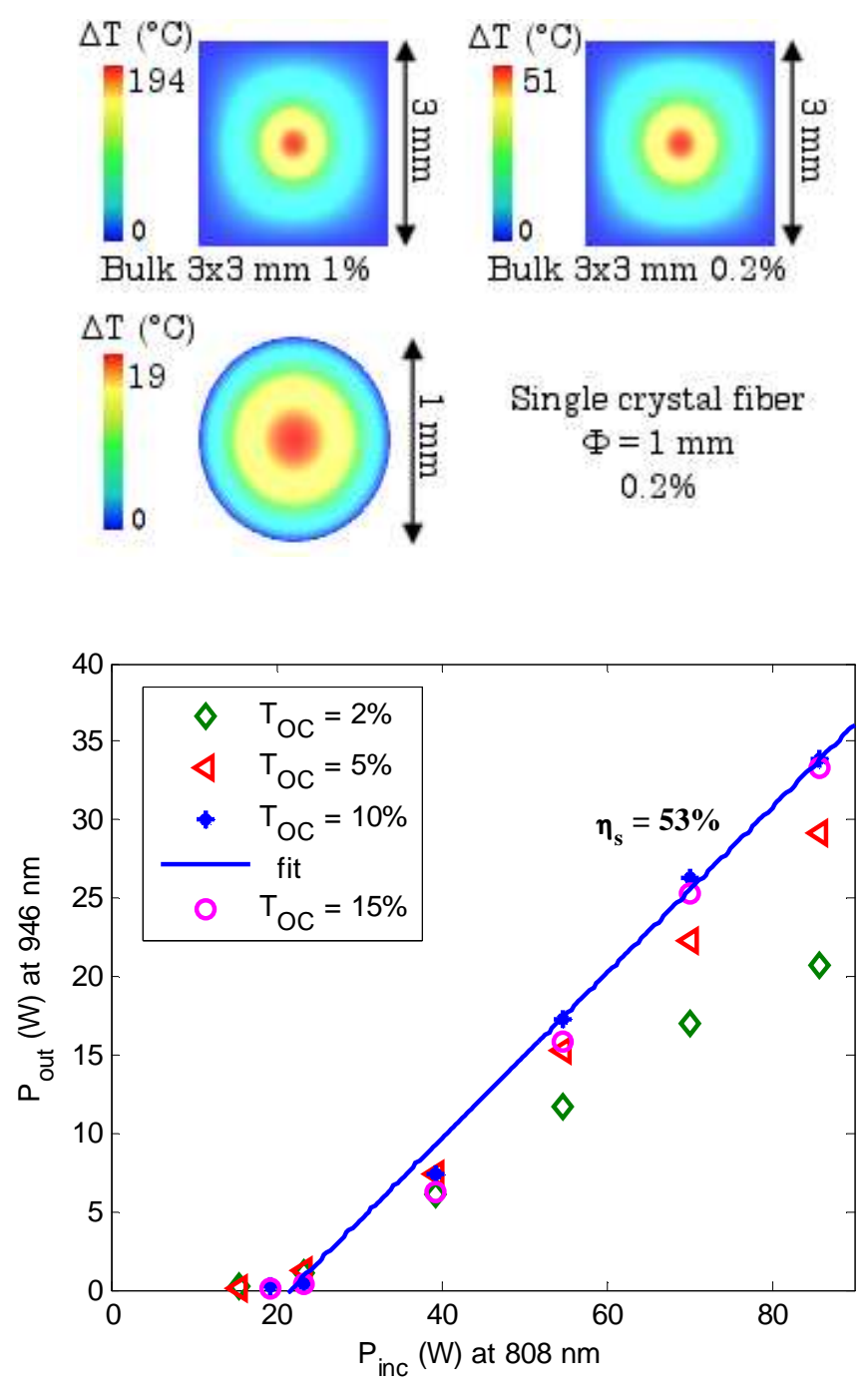


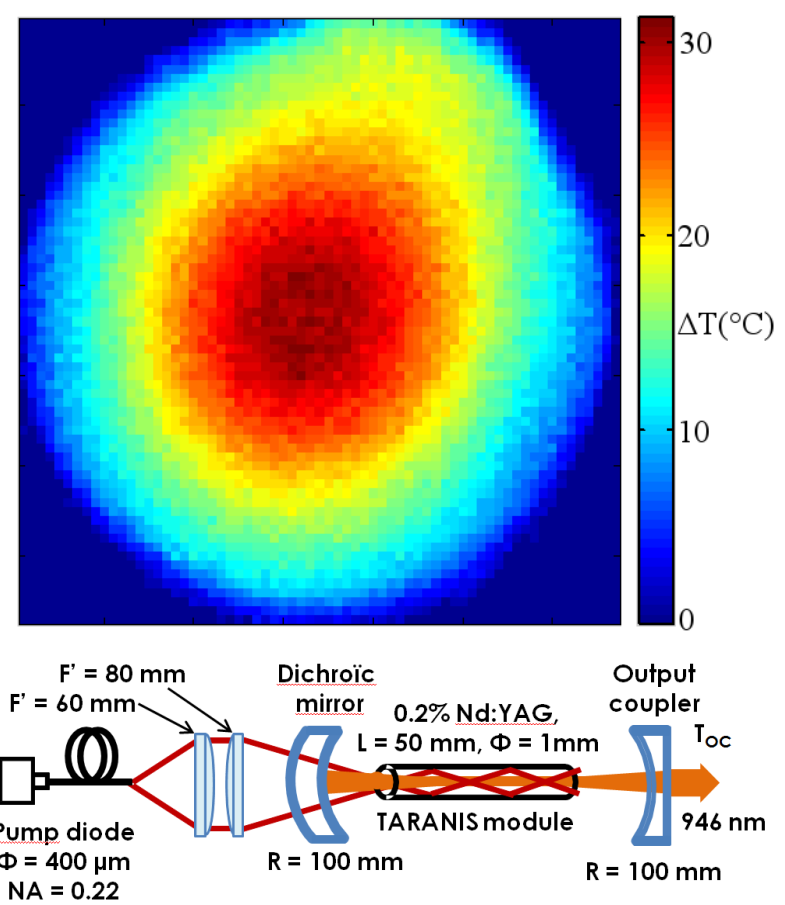

